\title{
Students' Processing of Differently Structured Text Materials Focused on Agricultural Waste Disposal Using Eye-tracking
}

\author{
Kristýna Mudrychová1, Martina Houšková Beránková ${ }^{1}, T^{1}$ ereza Horáková1, Milan Houška1 ${ }^{1}$, Jitka Mudrychová2 \\ ${ }^{1}$ Department of Systems Engineering, Czech University of Life Sciences Prague, Czech Republic \\ ${ }^{2}$ Calvià Primary Care Center, Health Service of Baleares, Baleares, Spain
}

\begin{abstract}
This study was focused on agricultural waste disposal (AWD) textual materials. Two educational texts are compared: designed texts traditionally with no purposeful design and structured knowledge texts, including the textual form of knowledge units. Eye-tracking technology is employed for retrieving the values of critical indicators specifying the way of reading the texts. We analysed users' visual attention and looking behaviour during the reading process. Thirty-three students worked with 45 pieces of educational texts accompanied by a didactic test. Statistical analyses show statistically significant differences neither in any indicator within studying the texts nor in the users' success rate in the didactic test. The users can work with the knowledge structured texts equivalently with the designed texts in the traditional way. The positive effect for AWD is that users can process knowledge structured texts with better results.
\end{abstract}

\section{Keywords}

Agricultural waste disposal (AWD), eye tracking, knowledge unit (KU), knowledge engineering, reading process, areas of interest.

Mudrychová, K., Houšková Beránková, M., Horáková, T., Houška, M. and Mudrychová, J. (2021) “Students' Processing of Differently Structured Text Materials Focused on Agricultural Waste Disposal Using Eye-tracking", AGRIS on-line Papers in Economics and Informatics, Vol. 13, No. 4, pp. 85-99. ISSN 1804-1930. DOI 10.7160/aol.2021.130408.

\section{Introduction}

Waste disposal in agriculture and the environment

The importance of waste disposal nowadays is noticeable concerning new technologies and environmental studies. Waste disposal in agriculture is one part of the whole waste disposal. It is advantageous, almost inexpensive and renewable energy with a massive amount of and wide varieties in agriculture. Those wastes can be used in agriculture as feed for farm animals (livestock), thrown away directly or burned. Therefore, based on recent studies, the focus is to utilise the efficiency of waste disposal in agriculture with less impact on the environment or even improve the quality of the environment. There are commonly known processes such as anaerobic digestion (Golecha and Gan, 2016; Mancini et al., 2018) and fermentation (Ji et al., 2014; Reichardt et al., 2009) that can be the improvement done. Other processes such as gasification, pyrolysis (Catto et al., 2010; Lim et al., 2012) or chemical treatments (Horax et al., 2017; Shen et al., 2012) of biomass which produces gas (Park et al., 2017; Wang et al., 2019), liquid (Yue et al., 2016) or carbon-rich solid materials (Horax et al., 2017; Shen et al., 2012; Wang, Wu and Sun, 2018) through synthesis could be used for the improvements as well.

That is why it is essential to start teaching students mentioned above. The authors' focus was on university students who have already some experience with waste processing due to their university studies. We focused specifically on textual materials from waste disposal and how to improve students' transfer of knowledge about waste disposal. Students usually have a pretty wide range of textual materials where teachers make sure their students get the necessary knowledge for their studies.

Considering learning processes and strategies, Oxford et al. (2017) or Griffiths et al. (2013) provide a different view on learning processes and their division, description, or even determination of which learning strategies should be used. Also, those authors used different approaches in various 
research disciplines. The research done by Oxford and Randall (2017) was focused on the process of learning foreign languages to find out and learn how to manage and control the effort of learning a new language. However, the research done by Griffiths et al. (2012) looked at the same problem and discovered that learning strategies are often chosen and created by the learner, not by the teacher. It is clear from studies that many authors, such as those mentioned above, agree with some basic standards about strategies, typically that the involvement of the learner and his/her responsibility for the learning process is significant (Griffiths et al., 2017).

Moreover, a positive impact on learning performance can be observed when teachers use more visual materials, pictures, and specific words to research learning. Nevertheless, the process and the integration of textual and visual materials require much effort. The solution should be to have more visual materials in the process of learning; these include verbal cues that can guide the learners. Therefore, learners can use them more efficiently and match their attention to visual materials with the one to textual materials and vice versa (Ching, 2012; Mayer, 2014; Mayer, Lee and Peebles, 2014; Navarro et al., 2015).

Based on the above, the authors decided to test students on pieces of textual materials that provided information about waste treatment in different conditions and locations, waste treatment, and other related procedures. Those textual materials were already used in Horáková and Houška (2014) study or formerly in Enviregion (2014) textbook.

\section{Knowledge vs traditionally structured text}

This study differentiates the educational text into two shapes: designed texts traditionally and knowledge structured texts. The information or didactic content of the text is the same, but the presentation style of the texts are different. Traditionally written texts are written in a manner following the educational standards by the authorities. Still, the author's personality and writing style can still influence textual materials, in which sentences are not built for a learning purpose. It is hard for authors to separate their writing style even if they follow the standards by which those books, textual materials, and other literary pieces used in education should be written.

On the other hand, the style of knowledge structured texts is perfectly aligned with the process of knowledge representation, such as production rules or, preferably, knowledge units. The personal style of writing of individual authors is suppressed, and so, the traditionally designed text, which is written in books, articles, journals, and others. In our study, traditionally created texts represent a standard, original text that gives us the same information as a knowledge structured text. Both types of texts provide us the same information and knowledge.

We can look at a knowledge unit (KU) such as an "information bit" or a kind of entity. In this study, we use the definition of a knowledge unit, divided into four parts. According to Dömeová et al. (2008), those four parts are as follows: problem situation (called part X), elementary problem (called part $\mathrm{Y}$ ), objectives of the elementary problem to solve (called part Z), and solution of the elementary problem (called part Q). Textual form of the KU is: if we solve a problem $\mathrm{Y}$ in a problem situation $\mathrm{X}$ subject to the objective $\mathrm{Z}$, then we should apply the solution Q. We used this definition of a knowledge unit for constructing knowledge structured texts, and part of the results was published in Mudrychová et al. (2017).

Knowledge unit can be represented in two forms, and one of them is structured, e. g.: $\mathrm{X}=$ to dispose of waste with minimal environmental damage, $\mathrm{Y}=$ when looking for the most suitable and efficient ways, $\mathrm{Q}=$ environmental aspects must be taken, $\mathrm{Z}=$ into account in addition to economic aspects. Another form is to formulate a knowledge unit in textual form, e. g.: "When looking for the most suitable and efficient ways to dispose of waste with minimal environmental damage, environmental aspects must be taken into account in addition to economic issues" (Horáková, Houška and Dömeová. 2017; Mudrychová, Houšková Beránková and Horáková, 2018; Houška and Houšková Beránková, 2006).

\section{Research focus}

Our research is focused on differences in the reading process of traditionally and knowledge structured text by users. It means that reading behaviour is measured in time units of eye movements through the whole reading process; measuring is by eyetracking technology.

This is related to visual attention and what does it mean for authors. Visual attention can be understood as a set of cognitive and psychological mechanisms that modulate visual information present to a respondent. Those processes allow for processing rapidly and accurately a relevant stimulus and separate it from irrelevant. It is necessary to integrate visual information 
into objects that can be successively identified and be recognised or remembered (Holmquist, 2011).

Research question: Are there differences between users' reading processes of knowledge and traditionally designed text?

If users' results are much significantly better in didactic tests and/or results of their reading processes are significantly faster, traditionally structured texts will be considered to re-write and re-structure to knowledge structured form.

Sub-research questions are as follows:

Sub-RQ1: Are there differences in looking behaviour during users' reading processes of knowledge and traditionally structured text? - it is related to HO1 and HO2.

Sub-RQ2: Are there differences in visual attention during users' reading processes of knowledge and traditionally structured text? - it is related to $\mathrm{HO} 3$ and HO4.

Sub-RQ3: Are there differences in visual attention during users' reading processes among parts of knowledge units? - it is related to H05 and HO6.

Above mentioned sub-research questions are elaborated into statistical hypotheses.

\section{Materials and methods}

Eye movements on the screen are tracked using two primary groups of parameters. One is based on eye fixations in particular areas of interest; the other operates with eye visits in the areas. Duration of a visit contains all the fixations that occurred during one visit within the AOI. This variable contains the saccadic duration (quick jumps from one fixation to the other) among those fixations within that AOI until a fixation occurred outside the AOI. Visit count is the total number of all visits within the AOI. On the other hand, the duration of fixations is the sum of durations of all distinct fixations in the corresponding area within an AOI (Kim et al., 2012).

We used mean values and metrics which provide Tobii Studio in relation to the methodology of Holmquist (2011) and based on studies such as Shokishalov and Wang (2019) and Norqvist et al. (2019). Eye tracker trials range of users' lost attention were between $300 \mathrm{~ms}$ to $1800 \mathrm{~ms}$.

Educational, scientific research and other creative activities at the Czech University of Life Sciences Prague (CZU) must be following the CZU Code of Ethics. The Ethical Committee of the CZU supervises it. The opinion of the CZU Ethics Committee is not required for the implementation of IGA FEM grants, only if the planned research could significantly interfere with the personal integrity of the examined subjects, such as animal experiments and other similar. The IGA FEM management will contact the CZU Ethics Committee and will request an opinion on this matter. As the research whose results are published in the article does not fall into this category, the opinion of the CZU Ethics Committee was not required. The authors got the confirmative approval of the mentioned information above.

\section{Procedure of experiment}

The experiment itself started with an introduction to avoin any misunderstanding and interruption during the process, and a short questionnaire. Each participant had to fill up basic personal information, e. g., year of birth, sex, study programme etc. and also information about eyes and head injuries.

The eye-tracking part followed. First step of that is calibration, which is made automatically by the software. The calibration process was undertaken on average 2-3 times per participant. Second step is partcipants' work with stimuli under eye-tracking recording. Participants task was to read stimuli carefully and try to remember as much as they can. We prepared one document which included both types of texts - knowledge and traditional designed text. Stimuli consisted of 45 slides in the PDF file in total. The $1^{\text {st }}$ page contained instructions for participants. 22 slides with statemets regarding AWP followed. Half of the text slides were written in the traditional style, and half were in the knowledge style, they were in random positions within the text. Is was not allowed to go back to previous slides.

As mentioned in the introduction section, selected pieces of text were taken from a specific field of studies (studies of environment, waste, landscape, and others). Typically, the length of such designed texts was 3 to 5 rows, and every single piece of the text was presented on a single page of a PDF file. The font size of the text was 28 points, and the font type was set up as Calibri style, the interline used in the text was 10 points from the bottom of the high line type to the top of the standard line type. Textual materials were presented as a centrally located object, black letters on a white page; no other colours were allowed to disturb other colours or objects participants. 
Third (last) part of eye-traking was focused on the didactic test, which was presented on last 22 slides of stimuli. The didactic test contained 22 questions; those questions were written in the form of a statement, and the participant had to accept or deny it. It was not allowed to go back to study text materials. We followed standard procedures in preparation for the didactic test (Pumilia-Gnarini et al., 2012). The didactic test was used as a control mechanism to see how participants react immediately after reading the textual material.

We used an eye-tracking laboratory at the CZU called HUBRU (Human Behavior Research Unit). There are available two computers with built-in Tobii Pro Eye Tracker X2-60. The experiment was conducted in a darkened room (the windows were darkened) with sound insulation for participants to concentrate on their tasks. Stimuli were controlled using the Tobii Pro Studio software. The eye tracker sampling rate was about $60 \mathrm{~Hz}$ (with a minimum and maximum error of 0 and $16.67 \mathrm{~ms}$, respectively).

The presentation of textual materials (both statements and questions) in PDF was on a computer. The viewing distance was $50 \mathrm{~cm}$ in front of the centre of the screen. Each participant worked with the same stimuli and always in the same design, the designed were not alternated.

\section{Areas of interest (AOI)}

Areas of interest (AOI) are described as part of the text or image on the screen highlighted by eye-tracking tools. Those parts of text or image are the most relevant for research and examine eye movements patterns such as words, sentences, and images (Holmquist et al. 2011; Mudrychová et al., 2017). Those areas of interest were created for text types (traditionally designed text and knowledge structured text). For knowledge structured text, the areas of interest were divided into four parts corresponding to the parts of the knowledge unit (X, Y, Z, Q). In the traditionally designed text, the AOIs were used on the same piece of information. In general, two types of areas of interest exist: static or dynamic. We only worked with static AOIs, and we collected statistics and data throughout the time spent on media, i.e., pdf file (Holmquist et al., 2011; Mudrychová, Houšková Beránková and Horáková, 2018).

\section{Creating the areas of interest within the stimuli}

Each screen with a traditionally designed/ knowledge structured text contained 4 areas of interest. The screens with didactic questions (test) always contained three AOIs - one contained the statement; two contained the TRUE/FALSE answers.

See Figure 1 for testing examples of constructing stimuli for knowledge structured text and traditionally structured text (Figure 2). All textual materials were extracted from the source Enviregion (2014). The translation of Figure 1 content is:" If we choose technology for waste disposal in order to achieve maximum efficiency, it is necessary to start by evaluating the amount and composition of waste.". The AOI 1 represents part of KU called X, the AOI 2 represents part Y, the AOI 3 represents part $\mathrm{Z}$, and the AOI 4 reprezents part Q.

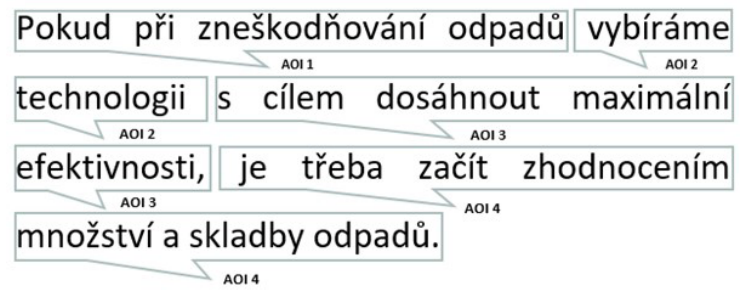

Source: authors' processing (source: Enviregion, 2014)

Figure 1: Knowledge structured example of construction KUs (AOIs) within the piece of text.

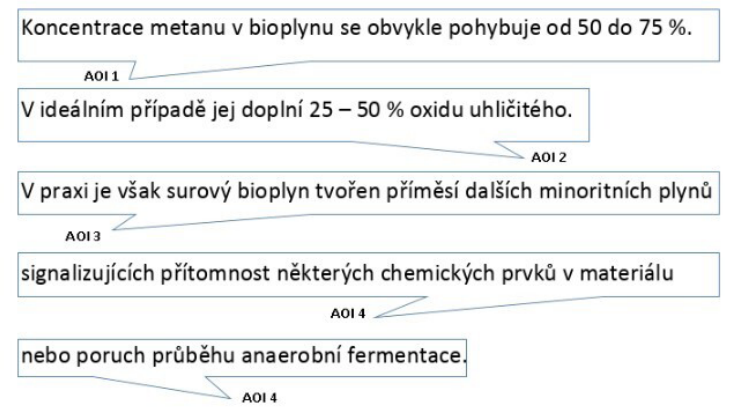

Source: authors' processing (source: Enviregion, 2014)

Figure 2: Traditionally structured example of construction AOIs within the piece of text.

The translation of Figure 2 content is: "The methane concentration in the biogas typically ranges from 50 to $75 \%$. Ideally, it is supplemented with 25 - 50\% carbon dioxide. In practice, however, raw biogas is formed by the addition of other minor gases signalling the presence of some chemical elements in the material or disturbances in the course of anaerobic fermentation.". AOIs represent parts of the traditional text which contain the same information as these in the KU.

Also, see examples in the original Czech language of the question with answers (Figure 3) 
directly exported from Tobii Pro Studio software. The translation of Figure 3 content is: "The environment does not have to be taken into account when disposing of waste. True/False".

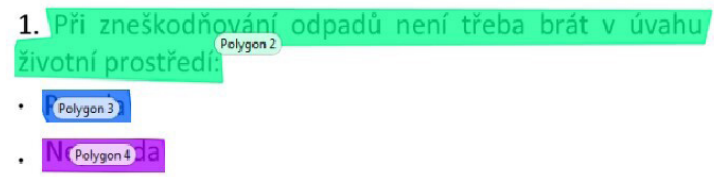

Source: authors' processing

Figure 3: Example of the didactic question with answers and AOI within the text.

\section{Participants and their selection}

In this study, the purposefully selected research sample of homogeneous respondents has been used. In particular, the sample consisted of university students of bachelor's and master's degrees in economic studies. The group contained 13 male students and 20 female students, all being 20 to 29 years old. Most of those students were righthanded. Only three of them were left-handed. None of the participants had dyslexia, nor did they have any neurological disorder. They all had a normal or corrected-to-normal vision. All participants provided consent before participating (signed the consent).

All participants had to go through the preview test option before starting the main eye-tracking recording. Each participant could use as much time as needed, so time was unlimited for them in this experiment. We used full-screen mode without any annoying elements. The record was made in one frame, and data from the TET (Tobii Eye Tracker) were separately stored in databases and were assigned to the individual participant. The entire procedure lasted for approximately 45-60 min.

\section{Evaluation}

The following metrics are used to evaluate this experiment (Mudrychová et al., 2017; Kim, Ritchie and Mccormick, 2012).

- Visit Duration (seconds, mean values): These metrics measure the duration of each visit within an AOI. This visit is defined as the interval of time between the first fixation on that particular AOI and the subsequent fixation outside that AOI.

- Total Visit Duration (seconds, mean values): These metrics measure the total duration of all visits within the active AOI.

- Total Fixation Duration (seconds, mean values): These metrics measured the duration of each fixation within an AOI and were presented in work of Mudrychová, Houšková Beránková, and Horáková (2018).

- Fixation Count (some occurrences, mean values): These metrics measure the number of times the participant fixates on an AOI.

- Analysis of Variance (ANOVA) is used to determine the differences among the mean values of the fixation count among the AOIs representing each part of knowledge units (X, Y, Z, Q) in the knowledge structured text. Furthermore, ANOVA is used for comparison of the mean values of the Fixation Count among the AOIs representing each part of the knowledge unit and corresponding parts of the traditionally structured text. The samples of knowledge structured texts and traditionally structured texts are considered independent even though those texts represent the same piece of explicit knowledge and differ only in the form of the representation. This method is related to null hypotheses that are listed in the Results chapter.

- Consequently, the non-parametric test for independent measures is employed as another method for analysing the hypotheses listed in the Results chapter: H0.1 through H04. As usual, the hypotheses are formulated, i.e., the null hypothesis supposes that no difference between the mean values of the parameters mentioned above exists at the significant level alpha, such as in the study of (Mudrychová et al., 2017).

\section{Statistical hypotheses}

The complete list of six null hypotheses tested for the statistical analysis follows. The third null hypothesis (H0.3) has already been tested in the work of Mudrychová, Houšková Beránková and Horáková (2018). However, it is essential to incorporate H0.3 among the others to achieve a complex overview of the results of the eyetracking experiment that has been carried out to understand users/readers' processes and if the difference between textual styles is essential for them or not.

- H0.1: There is no difference in the mean values of Visit Duration of all participants between the knowledge structured text and the traditionally designed text. 
- H0.2: There is no difference in the mean values of Total Visit Duration of all participants between the knowledge structured text and the traditionally designed text.

- H0.3: There is no difference in the mean values of Total Fixation Duration of all participants between the knowledge structured text and the traditionally designed text; it was already presented in the study of Mudrychová et al. (2018).

- H0.4: There is no difference in the mean values of the Fixation Count of all participants between the knowledge structured text and traditionally designed text.

- H0.5: There is no difference in the mean values of the Fixation Count among the AOIs representing each part of knowledge units (X, Y, Z, Q).

- H0.6: There is no difference in the Fixation Count's mean values among the AOIs representing each part of the knowledge unit and corresponding parts of the traditionally designed text.

\section{Statistical analysis}

As the first step of the statistical analysis, some elementary characteristics were calculated. As the second step of the analysis, the Shapiro-Wilk W test (Schmidt et al., 2017) was used to examine whether selected data was normally distributed. The third step consisted of using the relevant parametric or non-parametric test for testing the average values (arithmetic mean) of indicators measured for the comparison of two types of texts (knowledge and traditional design). Non-parametric tests for two independent measures were used for the data of variables: Total Fixation Duration, Fixation Count, Visit Duration, and Total Visit Duration. Parametric test, i.e., One-Way Analysis of Variance (ANOVA), was used to determine fferences among the average values of the Fixation Count among the AOIs representing parts of KUs. Moreover, ANOVA was used to determine the average values of the Fixation Count within the AOIs representing each part of the KU and the equivalent part of the traditionally structured text. Post-hoc analysis and Scheffé's test was used. This was chosen as it is typically used for unequal sample sizes, and Scheffé's method controls the overall confidence level.

\section{Results and discussion}

The didactic test checked knowledge transfer. The results of the experiment were summarised.
The students reached the success rate of more than $62.3 \%$ of correct answers in the didactic test. We see the didactic test as successful as it passed the limit of $60 \%$ of correct answers (PumiliaGnarini et al., 2012). The correct answers in the didactic test also gave researchers different results for correct answers for knowledge structured text and traditionally designed text separately. Students reached $50.7 \%$ of correct answers for questions from knowledge structured texts and $49.3 \%$ of correct answers for questions om the traditionally designed text; part of the results was published in the work of (Mudrychová, Houšková Beránková and Horáková, 2018).

We have considered the correlation between the reading performance of knowledge units (knowledge structured text) and areas of interest in the case of traditionally structured text. Also, that correlation we related to every metric we wanted to investigate - Visit Duration, Total Visit Duration, Fixation Count and Total Fixation Count. We focused on reading performance and its differences across different structured texts, as described in Table 1.

The difference in the reading performance of different structured texts

\section{Group of variables: Visit Duration, Total Visit Duration, Total Fixation Duration, Fixation Count}

Data were left-skewed for all results of the metrics such as Total Visit Duration, Fixation Count and Total Fixation Count. The results of the Shapiro-Wilk W test were as follows: $W=0.91795$ (knowledge structured text), $p=0.00 \quad$ (knowledge structured text), and $W=0.93602$ (traditionally designed text), $p=0.00$ (traditionally designed text); $\mathrm{p}$-values for both cases were lower than the significance level $\alpha=0.05$; the null hypotheses regarding the normality of the distribution of the data was rejected. Wald-Wolfowitz test was chosen for nonparametric testing (Table 1).

In the Wald-Wolfowitz test, was grouping variable "Type of text (knowledge structured text or traditionally designed text)" was used.

$P$-values for all tested cases (see Table 1) were higher than the significance level $\alpha=0.05$. The null hypotheses $\mathrm{H} 0.1, \mathrm{H} 0.2, \mathrm{H} 0.3$, and $\mathrm{H} 0.4$ the test was not rejected.

The $p$-value of $Z$ adjusted for measured mean values of all participants of the Visit Duration indicator was $p=0.393$. Therefore H0.1 was not rejected. 


\begin{tabular}{|c|c|c|c|c|c|c|c|c|c|c|}
\hline Variable & $\begin{array}{c}\text { Valid N } \\
\text { Know. Text }\end{array}$ & $\begin{array}{c}\text { Valid N } \\
\text { Tra. Text }\end{array}$ & $\begin{array}{c}\text { Mean } \\
\text { Know. Text }\end{array}$ & $\begin{array}{c}\text { Mean } \\
\text { Tra. Text }\end{array}$ & $Z^{a}$ & $p$-value ${ }^{*}$ & $Z$ adj. ${ }^{\text {b }}$ & $\begin{array}{l}\text { p-value } \\
\text { of } Z \text { adj.." }\end{array}$ & $\begin{array}{c}\text { No. } \\
\text { of runs }{ }^{\mathrm{c}}\end{array}$ & $\begin{array}{c}\text { No. } \\
\text { of ties }\end{array}$ \\
\hline Visit Duration & 363 & 363 & 2.859 & 2.948 & -0.891 & 0.373 & 0.854 & 0.393 & 352 & 160 \\
\hline $\begin{array}{l}\text { Total Visit } \\
\text { Duration }\end{array}$ & 363 & 363 & 8.574 & 8.905 & -0.966 & 0.334 & 0.928 & 0.353 & 351 & 59 \\
\hline $\begin{array}{l}\text { Total Fixation } \\
\text { Duration }\end{array}$ & 363 & 363 & 6.330 & 5.941 & 0 & 1.000 & -0.037 & 0.970 & 364 & 89 \\
\hline Fixation Count & 363 & 363 & 33.675 & 33.725 & -0.074 & 0.941 & 0.037 & 0.970 & 363 & 304 \\
\hline
\end{tabular}

Note: Know. Text $=$ Knowledge Text, Tra. Text $=$ Traditional Text, No. $=$ number, adj. $=$ adjusted

${ }^{a} Z$ represents scores of measures of standard deviation. The $Z$-value measures the difference between an observed statistic and its shypothesised population parameter in units of the standard deviation.

${ }^{\text {b }} Z$ adjusted represents scores that estimate the number of false positives for a given confidence level and adjust the critical $\mathrm{p}$-value accordingly,

${ }^{c}$ No. of runs represents two independent samples that are ranked in increasing order. Each value is coded as 1 or 2 and the total number is summed up in the total number of runs. The number of runs is the number of group changes plus one.

${ }^{\mathrm{d}}$ No. of ties represents ties involving observations from the two groups. Both the minimum and maximum numbers of runs possible are calculated.

${ }^{*} \mathrm{p}<.05$

Source: authors' processing, software used: STATISTICA 12 (StatSoft)

Table 1: Non-parametric test of knowledge structured text and traditionally designed text: Visit Duration, Total Visit Duration, Total Fixation Duration, Fixation Count-Wald-Wolfowitz test.

There is no difference between the knowledge structured text and the traditionally designed text for the mean values of Visit Duration. Those mean values describe time (in seconds) as the duration of each visit within an AOI spent by those participants.

The $p$-value of $Z$ adjusted for tested mean values of all participants of the Total Visit Duration indicator was $p=0.353$. Therefore H0.2 was not rejected. There is no difference between the knowledge structured text and the traditionally designed text for the mean values of Total Visit Duration exists. Those mean values describe time (in seconds) as the total duration of all visits within an AOI spent by those participants.

The $p$-value of $Z$ adjusted for tested mean values of all participants of the Total Fixation Duration indicator was $p=0.970$. Therefore $\mathrm{H} 0.3$ was not rejected. There is no difference between the knowledge structured text and the traditionally designed text for the mean values of Total Fixation Duration. Those mean values describe time (in seconds) as the total fixation duration of all visits within an AOI spent by those participants. The results for this selected variable have been presented in the work of Mudrychová, Houšková Beránková, and Horáková (2018).

The $p$-value of $Z$ adjusted for measured mean values of all participants of the Fixation Count indicator was $p=0.970$. Therefore H0.4 was not rejected. There is no difference between the knowledge structured text and the traditionally designed text for the mean values of the Fixation Count.
Those mean values describe time (in seconds) as the fixation count of all visits within an AOI spent by those participants.

\section{Group of variables: Fixation Count among the AOIs representing parts of KUs}

Results of the Shapiro-Wilk W test were as follows: $W=0.93889(\mathrm{X}), p=0.06306(\mathrm{X}), W=0.94236(\mathrm{Y})$, $p=0.07956(\mathrm{Y}) ; W=0.96620(\mathrm{Z}), p=0.383(\mathrm{Z}) ; W$ $=0.97260(\mathrm{Q}), p=0.5521(\mathrm{Q})$ (Table 2). In all cases, the $\mathrm{p}$-values were higher than the significance level $\alpha=0.05$; the null hypothesis regarding the normality of the distribution of the data was not rejected. Consequently, one-way ANOVA was used. The post-hoc analysis was carried out using Scheffé's test (Table 3). Levene's test did not reject the null hypothesis.

\begin{tabular}{|l|c|c|c|c|}
\hline Variable & df1 $^{\mathbf{a}}$ & df2 $^{\mathrm{b}}$ & $F^{\mathrm{c}}$ & $p$-value (sig.) \\
\hline Results & 1.047 & 5.712 & 1.832 & 0.145 \\
\hline
\end{tabular}

Note: Levene's test tests the null hypothesis that the population variances are equal or not. That is called homogeneity of variance or homoskedasticity.

a df1 represents the ANOVA test which involves comparing known means in sets of data. That represents the number of cells that are free to vary to get to a given grand mean.

${ }^{\mathrm{b}} \mathrm{df} 2$ represents the total number of observations in all cells. That means degrees of freedoms lost as the cell means are set.

${ }^{\mathrm{c}} \mathrm{F}$ represents an F-test of equality of variances. This test tests the null hypothesis that two normal populations have the same variance. F-value is used to calculate the p-value, which is used to decide the statistical significance of the terms and models. ${ }^{*} \mathrm{p}<.05$

Source: authors' processing, software used: STATISTICA 12 (StatSoft)

Table 2: Levene's test of homogeneity of each part of the knowledge unit X, Y, Z, Q. 


\begin{tabular}{|l|c|c|c|c|c|}
\hline Effect & SUM of square & df $^{\mathbf{b}}$ & Mean square & $\mathbf{F}^{\mathbf{d}}$ & p-value (sig.) \\
\hline Absolute value & 1132016 & 1 & 1132016 & 654.129 & 0.000 \\
\hline Type of KU & 24757 & 3 & 8252 & 4.769 & 0.004 \\
\hline Error & 221513 & 128 & 17301 & & \\
\hline
\end{tabular}

Note: One-way ANOVA is used to determine whether any of the differences between the means are statistically significant. Compare the p-value to set up a significance level to assess the null hypothesis.

a Sum of the square is the sum of the squares of the deviations of all the observations from their mean.

${ }^{b}$ df represents the ANOVA test which involves comparing known means in sets of data. That represents the number of cells means that are free to vary to get to a given grand mean.

${ }^{c}$ Mean square represents an estimate of the population variance. This statistic is calculated by dividing the corresponding sum of squares by the degrees of freedom.

${ }^{\mathrm{d}} \mathrm{F}$ represents an F-test of equality of variances. This test tests the null hypothesis that two normal populations have the same variance. F-value is used to calculate the p-value, which is used to decide about the statistical significance of the terms and models.

${ }^{*} p<.05$

Source: authors' processing, software used: STATISTICA 12 (StatSoft)

Table 3: One-way ANOVA of each part of the knowledge unit X, Y, Z, Q.

The $p$-value provided the results for rejecting H0.5. It means that at least one difference exists in the mean values of the Fixation Count among the AOIs representing each part of the KU. The post-hoc analysis was carried out using Scheffé's test. The results of Scheffé's test of each part of the KU indicated that there was a significant difference between parts $\mathrm{X}$ and $\mathrm{Y}$ and $\mathrm{X}$ and $\mathrm{Q}$, as highlighted in Table 4. The p-values were significant for variables $\mathrm{X}$ and $\mathrm{Y}$ and variables $X$ and $Q$. The difference between those two combinations of individual parts of the knowledge unit was significant.

The difference lies in that the results from the Fixation Count of participants and its mean values were higher for the part $\mathrm{Y}$ if we compare results of parts $\mathrm{X}$ and $\mathrm{Y}$. If we think about the difference between parts $\mathrm{X}$ and $\mathrm{Q}$, the results for the Fixation Count of participants and its mean values were higher for the part Q.

\begin{tabular}{|c|c|c|c|c|}
\hline Type of KU & $\mathbf{X}$ & $\mathbf{Y}$ & $\mathbf{Z}$ & $\mathbf{Q}$ \\
\hline $\mathbf{X}$ & & 0.031 & 0.546 & 0.013 \\
\hline $\mathbf{Y}$ & 0.031 & & 0.489 & 0.991 \\
\hline $\mathbf{Z}$ & 0.546 & 0.489 & & 0.317 \\
\hline $\mathbf{Q}$ & 0.013 & 0.991 & 0.317 & \\
\hline
\end{tabular}

Source: authors' processing, software used: STATISTICA 12 (StatSoft)

Table 4: Schaffe's test of all individual parts of knowledge unit X, $\mathrm{Y}, \mathrm{Z}, \mathrm{Q}$.

Schaffe's test is a part of post-hoc analysis of ANOVA. The Scheffé's test typically corrects alpha level for complex and straightforward comparisons of mean values. A complex comprising of mean values involves comparing more than one pair of means simultaneously.
The results of Levene's test showed no data indicating that the variance in each group was significantly different (i.e., the dispersion homogeneity condition was met). In summary, the difference between part $\mathrm{X}$ of the knowledge unit and AOI 1 of the traditionally structured text has not been proven. The same result was obtained for part $\mathrm{Y}$ of the knowledge unit and AOI 2, part $\mathrm{Z}$ of the knowledge unit and AOI 3, and part Q of the knowledge unit and AOI 4.

\section{Group of variables: Fixation Count within the AOIs representing each part of the $\mathrm{KU}$ and the equivalent part of the traditionally designed text}

The results of the Shapiro-Wilk $\mathrm{W}$ test were as follows (Table 5): $W=0.92191$ (AOI 1), $p=0.20071$ (AOI 1), $W=0.94540$ (AOI 2), $p=0.09765(\mathrm{AOI} 2) ; W=0.97410(\mathrm{AOI} 3)$, $p=0.60099$ (AOI 3); $W=0.97051$ (AOI 4), $p=0.49429$ (AOI 4). In all cases, the $p$-values were higher than the significance level $\alpha=0.05$; the null hypotheses regarding the normality of the distribution of the data selected were not rejected. Consequently, one-way ANOVA was used (Table 6). The result of significance or insignificance of each part of AOIs of traditionally designed texts and each part of the KU of knowledge structured texts were obtained using Schaffe's test. Levene's test proved the homogeneity.

There are no significant differences between those two types of parts of knowledge units and areas of interest of traditionally designed text, so H0.6 was not rejected. In this case, it means that there is no difference between part $\mathrm{X}$ of the knowledge unit and the corresponding AOI 1 of traditionally 


\begin{tabular}{|l|c|c|c|c|}
\hline Variable & df1 $^{\mathbf{a}}$ & df2 $^{\mathbf{b}}$ & $F^{\mathrm{c}}$ & p-value (sig.) $^{\mathbf{*}}$ \\
\hline X vs AOI 1 & 409.023 & 617.784 & 0.662 & 0.419 \\
\hline Y vs AOI 2 & 1027.109 & 542.958 & 1.892 & 0.174 \\
\hline Z vs AOI 3 & 17.955 & 574.771 & 0.031 & 0.860 \\
\hline Q vs AOI 4 & 289.560119 & 799.3728 & 0.362234 & 0.549394 \\
\hline
\end{tabular}

Note: Levene's test tests the null hypothesis that the population variances are equal or not. That is called homogeneity of variance or homoskedasticity.

a df1 represents the ANOVA test which involves comparing known means in sets of data. That represents the number of cells means that are free to vary to get to a given grand mean

${ }^{b} \mathrm{df} 2$ represents the total number of observations in all cells. That means degrees of freedoms lost as the cell means are set.

${ }^{\mathrm{c}} \mathrm{F}$ represents an F-test of equality of variances. This test tests the null hypothesis that two normal populations have the same variance. F-value is used to calculate the p-value, which is used to decide the statistical significance of the terms and models.

${ }^{*} p<.05$

Source: authors' processing, software used: STATISTICA 12 (StatSoft)

Table 5: Levene's test of Fixation Count for X and AOI 1, Y and AOI 2, Z and AOI 3, Q and $\mathrm{AOI} 4$.

\begin{tabular}{|l|c|c|c|c|c|}
\hline Effect: X vs AOI 1 & SUM of square & df $^{\mathrm{b}}$ & Mean squares & $F^{\mathrm{d}}$ & $p$-value (sig.) \\
\hline Absolute value & 401388 & 1 & 401388 & 2.682 & 0.000 \\
\hline Type of KU vs AOI & 1.953 & 1 & 1.953 & 131 & 0.258 \\
\hline Error & 95798 & 64 & 1.497 & & \\
\hline Effect: Y vs AOI 2 & SUM of squares & $\mathrm{df}$ & Mean square & $\mathrm{F}$ & p-value (sig.)* \\
\hline Absolute value & 581298 & 1 & 581298 & 305.812 & 0.000 \\
\hline Type of KU vs AOI & 6167 & 1 & 6167 & 3.245 & 0.076 \\
\hline Error & 121653 & 64 & 1901 & & \\
\hline Effect: Z vs AOI 3 & SUM of squares & $\mathrm{df}$ & Mean square & $\mathrm{F}$ & p-value (sig.)* \\
\hline Absolute value & 508292 & 1 & 508292 & 312 & 0.000 \\
\hline Type of KU vs AOI & 3.879 & 1 & 3.878788 & 0.002 & 0.961 \\
\hline Error & 104232 & 64 & 1629 & & \\
\hline Effect: Q vs AOI 4 & SUM of squares & $\mathrm{df}$ & Mean square & $\mathrm{F}$ & $\mathrm{p}$-value (sig.)* \\
\hline Absolute value & 814741 & 1 & 814741 & 371 & 0.000 \\
\hline Type of KU vs AOI & 1196 & 1 & 1196 & 0.545 & 0.463 \\
\hline Error & 140472 & 64 & 2195 & & \\
\hline
\end{tabular}

Note:

a Sum of the square is the sum of the squares of the deviations of all the observations from their mean.

${ }^{b} \mathrm{df}$ represents total degrees of freedom. It is the amount of information in data. The analysis uses that information to estimate the values of unknown population parameters.

${ }^{\mathrm{c}}$ Mean square represents an estimate of the population variance. This statistic is calculated by dividing the corresponding sum of squares by the degrees of freedom.

${ }^{\mathrm{d}} \mathrm{F}$ means $\mathrm{F}$-test and is used to test if a relationship exists between the dependent and independent variables. This test is based on the F distribution is used. The statistic is a ratio of the model mean square and the residual mean square.

${ }^{*} p<.05$

Source: authors' processing, software used: STATISTICA 12 (StatSoft)

Table 6. One-factor ANOVA for Fixation Count - the difference between each part of the knowledge unit X, Y, Z, Q and the corresponding part of AOI 1, AOI 2, AOI 3, AOI 4 of traditionally structured texts

designed text, part $\mathrm{Y}$ of the knowledge unit $\mathrm{Y}$ and the corresponding AOI 2, part Z of the knowledge unit and the corresponding AOI 3, part $\mathrm{Q}$ of the knowledge unit and the corresponding AOI 4.
We report in our study, as mentioned above, that no difference between knowledge structured text and traditionally designed text in all eye-tracking indicators, such as Visit Duration, Total Visit Duration, Fixation Count, and Total 
Fixation Duration. By using the non-parametric test for independent measures, the existence of this difference was tested. The non-parametric test provided results where the p-values were significantly higher than $\alpha=0.05$. That is why the null hypothesis was not rejected at the significance level for hypotheses H0.1 through H0.4. Moreover, we did not extend the hypothesis H0.6 related to differences between each part of the knowledge unit (X, Y, Z, Q) and the corresponding part of the traditionally designed text (AOI 1, AOI 2, AOI 3, AOI 4). On the other hand, a difference among the parts of the knowledge unit related to hypothesis H0.5 was proven to exist, specifically between parts $\mathrm{X}$ and $\mathrm{Y}$ and $\mathrm{X}$ and $\mathrm{Q}$.

The answer to our research question is that users can work with knowledge and traditionally designed texts equivalently. Knowledge structured text and its form does not cause harm to their reading process. The results from the didactic test were slightly better from answered questions that followed knowledge structured texts, but not significantly higher. We can conclude that the conversion of texts will not add any new value to users from knowledge structured to traditionally designed texts. The most positive fact is that if users have to use any organisation manual, regulation or guideline, they can proceed with knowledge structured text and understand it similarly in a better way than traditionally structured text. That means for organisations that if they use such textual materials for their organizational processes, their employees can understand better what they should do, and there should be the elimination of wrong proceeding with the process (also in AWD). For example, users using manuals on how they have to proceed with hazardous waste treatment will understand those processes better, and there is a potential decrease of cases with human factor impact on hazardous waste treatment (poor handling and transport, improper storage and others) (Saedi-Mobarakeh et al., 2019). It has an impact on employees' ability to understand it. Also, it can have an impact on their competencies and the effectiveness of their work. We are convinced that our results in $\mathrm{H} 0.5$ support this idea. From the results, we found out that participants focused more on the part of knowledge units $\mathrm{Y}$ and $\mathrm{Q}$ than $\mathrm{X}$. It means they focused more on elementary problems and solutions to the elementary problem than on problem situations. Those parts of the knowledge unit are the most important from the learning process perspective, and those results are desirable.
This study can follow in future research studies such as Shotter (2013), who provided reading times on preview/target words. Those words were embedded in a few sentences and were moderately constrained. The idea shared by the target/synonym word can be highly predicted. On the other hand, authors such as Metusalem et al. (2012) and Roland et al. (2012) focused on the whole context in text and that it might constrain a particular idea that leads to a faster reading process of the target. Other authors followed that idea and developed it, even more, DeLong et al. (2014) and Smith and Levy (2013) discovered the occurrence that suggested the sentence constraint can lead readers to generate expectations about upcoming words in the text. It is often a phenomenon that readers make a specific, unitary prediction of the upcoming word. It aligns with already mentioned studies of DeLong et al. (2014) and Smith and Levy (2013) about this interpretation with the idea of pre-activation/anticipation. That pre-activation/ anticipation happens in a qualitatively graded mode.

The difference between this study and the study of Stein (2001) is that eye-tracking technologies were not used to investigate students' physical pre-requisites. Stein (2001) worked with neurodevelopmental disorders of students and screen reading skills only. As mentioned from the perspective, we focused on their reading process to make the knowledge transfer process more comfortable or faster for them. Differences among students in how they read, process and evaluate text can be seen, and the difference among students and their possible disorders can be checked (Stein, 2001). Dyslexia is quite common among students and can be easily identified via eye-tracking technology. Few authors work with the assumption of dyslexia and the fact of different processing of words by students with or without dyslexia (Moody, 2010; Wigfield et al., 2014; Stein, 2001; Sim, Cassidy and Read, 2013).

AWD deals with many regulations, rules, and also technical issues. The gap consists of the unbalanced level of users' knowledge and not well-structured texts. Based on the above mentioned, we are partially compliant with the study of Mateer et al. (2020) as they focused on predicting the proper waste disposal in correlation with users observations. It is similar to our study in that case, in that we observed our users and how they process textual materials to see their performance. 


\section{Conclusion}

In the study, we used different textual materials focused on agricultural waste disposal (AWD) to investigate the differences in the reading process of knowledge and traditionally structured text. We were able to identify that there are differences between those types of textual materials, but they are not for students. We could indicate specific cases where some differences were present (such as answering didactic tests after knowledgeconstructed texts). That could be very useful for a follow-up experiment needed to vary the differences between those different types of textual materials in the larger text (here we used 3 - 5 lines texts as mentioned in methodology). Also, there is a possibility of preparing more extensive textual materials and a more substantial didactic test. Moreover, there can be a comparison between languages and between native speakers with non-native speakers.

Not structured and semi-structured educational texts (whether a knowledge structured text or a traditionally designed text) will result in learning and reading difficulties for students. It can be an issue, especially in such studies as agricultural waste disposal (AWD) and processing of waste in agriculture in general. Waste management as a parent field is connected to how effectively process wastes and agriculture, crop production, animal production, agriculture machinery, and many others.

The primary limits of this study relate to the research sample. We purposefully chose the homogeneous group of the students to carry out the quantitative analysis. The inherent disadvantage of this approach is that the results are not to be generalised and exploited for other specific target groups. On the other hand, this is an opportunity for future research. We will define other relevant groups of potential beneficiaries of the research and their unique characteristics and extend the eye-tracking study. We will develop the assignment target group vs the most efficient educational texts for the group in the final state. This could provide waste disposal studies with a better overview for students.

Furthermore, after the study's success with students, it is possible to extend research groups as mentioned above and apply them in daily practice. As was mentioned in our study, our results are used for waste disposal studies and various other organisations that have processes recorded in the form of manuals, organisation regulations, guidelines, and other forms.ss. Those materials are usually in textual format, and if it is wrongly written (users do not understand textual material properly), they can incorrectly proceed with the process (even, e.g. the process of waste processing and any other waste disposal process).

\section{Acknowledgements}

The paper is supported by the grant project of the Internal Grant Agency of the FEM CZU "Knowledge engineering methods in the process of evaluating employee knowledge". No. 20161026.

Corresponding authors

Ing. Kristýna Mudrychová, Ph.D.

Department of Systems Engineering, Faculty of Economics and Management

Czech University of Life Sciences Prague, Kamýcká 129, 16500 Prague - Suchdol, Czech Republic

Phone: +420721858 560,E-mail: mudrychova@pef.czu.cz

ORCID: 0000-0002-1371-370X

\section{References}

[1] Burch, M. (2017) "Mining and Visualizing Eye Movement Data", Symposium on Visualization '17, Bangkok. ISBN 978-1-4503-5411-0. DOI 10.1145/3139295.3139304.

[2] Catto, M., Aliano, R., Carotti, A., Cellamare, S., Palluotto, F., Purgatorio, R., de Stradis, A. and Campagne, F. (2010) "Design, synthesis and biological evaluation of indane-2arylhydrazinylmethylene-1,3-diones and indol-2-aryldiazenylmethylene-3-ones as $\beta$-amyloid aggregation inhibitors", European Journal of Medicinal Chemistry, Vol. 45, pp. 1359-1366. ISSN 0223-5234. DOI 10.1016/j.ejmech.2009.12.029.

[3] DeLong, K. A., Quante, L. and Kutas, M. (2014) "Predictability, plausibility and two late ERP positivities during written sentence comprehension", Neuropsychologia, Vol. 61, pp. 150-162. ISSN 0028-3932. DOI 10.1016/j.neuropsychologia.2014.06.016. 
[4] Dömeová, L., Houška, M. and Houšková Beránková, M. (2008) "Systems Approach to Knowledge Modelling”, Hradec Kralove: GSOC. ISBN 978-80-86703-30-5.

[5] Enviregion (2014) “Textbook on Environmental Education". Enviregion, [On-line]. Available: http://ucebnice3. enviregion.cz/ [Accessed: 15 May 2014].

[6] Griffiths, D., Hingsburger, D., Hoath, J. and Ioannou, S. (2013) "Counterfeit Deviance Revisited", Journal of Applied Research in Intellectual Disabilities, Vol. 25, No. 5, pp. 471-480. ISSN 1468-3148. DOI 10.1111/jar.12034.

[7] Griffiths, J. D., Marslen-Wilson, W. D., Stamatakis, E. A. and Tyler, L. K. (2012) "Functional organisation of the neural language system: dorsal and ventral pathways are critical for syntax", Cerebral cortex, Vol. 23, No. 1, pp. 139-147. ISSN 1047-3211. DOI 10.1093/cercor/bhr386.

[8] Griffiths, M. D., Kuss, D. J., Lopez-Fernandez, O. and Pontes, H. M. (2017) "Problematic gaming exists and is an example of disordered gaming", Journal of Behavioral Addictions, Vol. 6, No. 3, pp. 296-301. ISSN 2062-5871. DOI 10.1556/2006.6.2017.037.

[9] Helm, S. (2007) "One reputation or many?: Comparing stakeholders' perceptions of corporate reputation", Corporate Communications: An International Journal, Vol. 12, No. 3, pp. 238-254. ISSN 1356-3289. DOI 10.1108/13563280710776842.

[10] Holmqvist, K., Nyström, M., Andersson, R., Dewhurst, R., Halszka, J. and van de Weijer, J. (2011) "Eye Tracking: A Comprehensive Guide to Methods and Measures", Oxford: Oxford University Press. ISBN 978-0198738596.

[11] Horax, K. M., Bao, S. J., Wang, M. Q. and Li, Y. A. (2017) "Analysis of graphene-like activated carbon derived from rice straw for application in supercapacitor", Chinese Chemical Letters, Vol. 28, No. 12, pp. 2290-2294. ISSN 1001-8417. DOI 10.1016/j.cclet.2017.11.004.

[12] Horáková, T., Houška, M. and Dömeová, L. (2017) "Classification of the educational texts styles with the methods of artificial intelligence", Journal of Baltic Science Education, Vol. 16, No. 3, pp. 324-336. ISSN 1648-3898. DOI 10.33225/jbse/17.16.324.

[13] Houška, M. and Houšková Beránková, M. (2006) "Mathematical models for elementary knowledge representation", Scientia Agriculturae Bohemica, Vol. 37, No. 5, pp. 32-37. ISSN 1211-3174.

[14] Hout, M. C. and Goldinger S. D. (2011) "Incidental learning speeds visual search by lowering response thresholds, not by improving efficiency: Evidence from eye movements", Journal of Experimental Psychology: Human Perception and Performance, Vol. 38, No. 1, pp. 90-112. ISSN 0096-1523. DOI 10.1037/a0023894.

[15] Huang, L. and Lin, C. (2011) "EFL learners' reading on mobile phones", The JALT CALL Journal, Vol. 7, No. 1, pp. 61-78. ISSN 1832-4215. DOI 10.29140/jaltcall.v7n1.108.

[16] Huang, Y.-M, Liang, T.-H., Su, Y.-N. and Chen, N.-S. (2012) "Empowering sPersonalised Learning with an Interactive E-Book Learning System for Elementary School Students", Educational Technology Research and Development, Vol. 60, No. 4, pp. 703-722. ISSN 1042-1629. DOI 10.1007/s11423-012-9237-6.

[17] Ching-I, W. (2012) "HCI and Eye Tracking Technology for Learning Effect", Social and Behavioral Sciences, Vol. 64, pp. 626-632. ISSN 1877-0428. DOI 10.1016/j.sbspro.2012.11.073.

[18] Ji, W. C., Shen, Z. M. and Wen, Y. J. (2014) "A continuous hydrothermal saccharification approach of rape straw using dilute sulfuric acid", BioEnergy Research, Vol. 7, pp. 1392-1401. ISSN 1939-1234. DOI 10.1007/s12155-014-9468-y.

[19] Kim Y.-S., Park C. and Wagner R. K. (2014) "Is oral/text reading fluency a "bridge" to reading comprehension?", Reading and Writing: An Interdisciplinary Journal, Vol. 27, pp. 79-99. ISSN 0922-4777. DOI 10.1007/s11145-013-9434-7.

[20] Kim, J.-H., Ritchie, R. B. J. and McCormick, B. (2012) "Development of a Scale to Measure Memorable Tourism Experiences", Journal of Travel Research, Vol. 51, pp. 12-25. ISSN 0047-2875. DOI $10.1177 / 0047287510385467$. 
[21] Kim, Y. S., and Wagner, R. K. (2015) "Text (Oral) Reading Fluency as a Construct in Reading Development: An Investigation of its Mediating Role for Children from Grades 1 to 4", Scientific studies of reading: the official journal of the Society for the Scientific Study of Reading, Vol. 19, No. 3, pp. 224-242. E-ISSN 1532-799X, ISSN 1088-8438. DOI 10.1080/10888438.2015.1007375.

[22] Korat, O. and Falk, Y. (2017) "Ten years after: Revisiting the question of e-book quality as early language and literacy support", Journal of Early Childhood Literacy. Vol. 19 , No. 2, pp. 206-223. ISSN 1468-7984. DOI 10.1177/1468798417712105.

[23] Lai, J., and Chang, C. (2011) "User attitudes toward dedicated e-book readers for reading: The effects of convenience, compatibility and media richness", Online Information Review, Vol. 35, No. 4, pp. 558-580. ISSN 1468-4527. DOI 10.1108/14684521111161936.

[24] Li, X. and Shen, W. (2013) "The joint effect of insertion of spaces and word length in saccade target selection in Chinese reading", Journal of Experimental Education, Vol. 36, No. S1, pp. S64-S77. ISSN 0022-0973. DOI 10.1111/j.1467-9817.2012.01552.x.

[25] Lin, P.-H., Su, Y.-N. and Huang, Y.-M. (2019) "Evaluating reading fluency behavior via reading rates of elementary school students reading e-books", Computers in Human Behavior. Vol. 100, pp. 258-265. ISSN 0747-5632. DOI 10.1016/j.chb.2018.10.004.

[26] Linder, D. E., Mueller, M. K., Gibbs, D. M., Alper, J. A., and Freeman, L. M. (2017) "Effects of an Animal-Assisted Intervention on Reading Skills and Attitudes in Second Grade Students", Early Childhood Education Journal, Vol. 46, pp. 323-329. ISSN 1082-3301. DOI 10.1007/s10643-017-0862-x.

[27] Liu, Z. (2005) "Reading behavior in the digital environment: Changes in reading behavior over the past ten years", Journal of Documentation, Vol. 61, No. 6, pp. 700-712. ISSN 0022-0418. DOI 10.1108/00220410510632040.

[28] Mancini, G., Papirio, S., Riccardelli, G., Lens, P.N.L. and Esposito, G. (2018) "Trace elements dosing and alkaline pretreatment in the anaerobic digestion of rice straw", Bioresource Technology, Vol. 247, pp. 897-903. ISSN 0960-8524. DOI 10.1016/j.biortech.2017.10.001.

[29] Mason, L., Pluchino, P., Tornatora, M. C. and Ariasi, N. (2013) "An Eye-Tracking Study of Learning from Science Text with Concrete and Abstract Illustrations", Journal of Experimental Education, Vol. 81, No. 3, pp. 356-384. ISSN 0022-0973. ISSN 0022-0973. DOI 10.1080/00220973.2012.727885.

[30] Mayer, R. E., Lee, H. and Peebles, A. (2014) "Multimedia Learning in a Second Language: A Cognitive Load Perspective", Applied Cognitive Psychology, pp. 356-384. ISSN 1099-0720. DOI 10.1002/acp.3050.

[31] Metusalem, R., Kutas, M., Urbach, T. P., Hare, M., McRae, K. and Elman, J. L. (2012) "Generalised event knowledge activation during online sentence comprehension", Journal of Memory and Language, Vol. 66, No. 4, pp. 545-567. ISSN 0749-596X. DOI 10.1016/j.jml.2012.01.001.

[32] Moody, A. (2010) "Using electronic books in the classroom to enhance emergent literacy skills in young children'", Journal of Literacy and Technology, Vol. 11. ISSN 1535-0975.

[33] Mudrychová, K., Houšková Beránková, M. and Horáková, T. (2018) "Value of Knowledge in the Process of Lifelong Education", $15^{\text {th }}$ International Conference on Efficiency and Responsibility on Education, Prague, pp. 235-242.

[34] Mudrychová, K., Houšková Beránková, M., Houška, M. and Dömeová, L. (2017) "Retrieving Knowledge from Texts: Design of an Experiment with Human Users", $14^{\text {th }}$ International Conference on Efficiency and Responsibility for Education, Prague, pp. 270-278.

[35] Navarro, O., Molina, A.I., Lacruz, M. and Ortega, M. (2015) "Evaluation of Multimedia Educational Materials Using Eye Tracking", Social and Behavioral Sciences, Vol. 197, pp. 2236-2243. ISSN 1877-0428. DOI 10.1016/j.sbspro.2015.07.366.

[36] Nikolova, M., Jainta, S., Blythe, H. I., and Liversedge, S. P. (2018) "Binocular advantages for parafoveal processing in reading", Vision Research, Vol. 145, pp. 56-63. ISSN 0042-6989. DOI 10.1016/j.visres.2018.02.005. 
[37] Norqvist, M., Jonsson, B., Lithner, J., Qwillbard, T. and Holm, L. (2019) "Investigating algorithmic and creative reasoning strategies by eye tracking", The Journal of Mathematical Behavior Vol. 5. ISSN 0732-3123. DOI 10.1016/j.jmathb.2019.03.008.

[38] Oxford, R. G. and Randall, M. Ch. (2017) "Neurosurgical Considerations in Craniofacial Trauma", Facial Plastic Surgery Clinics of North America, Vol. 24, No. 4, pp. 479-491. ISSN 1064-7406. DOI 10.1016/j.fsc.2017.06.002.

[39] Pappas, I., Sharma, K., Mikalef, P. and Giannakos, M. (2018) "Visual Aesthetics of E-Commerce Websites: An Eye-Tracking Approach", $51^{\text {st }}$ International Conference on System Sciences, Hawaii. ISBN 978-0-9981331-1-9. DOI 10.24251/HICSS.2018.035.

[40] Park, S., Yoon, Y. M., Han, S. K., Kim, D. and Kim, H. (2017) "Effect of hydrothermal pre-treatment (HTP) on poultry slaughterhouse waste (PSW) sludge for the enhancement of the solubilisation, physical properties, and biogas production through anaerobic digestion", Waste Management, Vol. 64, pp. 327-332. ISSN 0956-053X. DOI 10.1016/j.wasman.2017.03.004.

[41] Pumilia-Gnarini, P. M., Favaron, E., Pacetti, E., Bishop, J. and Guerra, L. (2012) "Handbook of Research on Didactic Strategies and Technologies for Education: Incorporating Advancements (2 Volumes)", 1st. ed., USA: IGI Global, p. 829. ISBN 978-1-4666-2122-0. DOI 10.4018/978-1-4666-2122-0.

[42] Rayner, K., Pollatsek, A., Ashby, J., and Clifton, C. (2012) "The Psychology of Reading". New York: Psychology Press. ISBN 9781848729759.

[43] Reichardt, N., Gniechwitz, D., Steinhart, H., Bunzel, M. and Blaut, M. (2009) "Characterisation of high molecular weight coffee fractions and their fermentation by human intestinal microbiota", Molecular Nutrition and Food Research, Vol. 53, pp. 287-299. ISSN 1613-4133. DOI 10.1002/mnfr.200700509.

[44] Ren, G.-Q. and Yang, Y. (2010) "Syntactic boundaries and comma placement during silent reading of Chinese text: evidence from eye movements", Journal of Research in Reading, Vol. 33, No. 2, pp. 168-177. ISSN 0141-0423. DOI 10.1111/j.1467-9817.2009.01406.x.

[45] Roland, D., Yun, H., Koenig, J. P. and Mauner, G. (2012) "Semantic similarity, predictability, and models of sentence processing", Cognition, Vol. 122, pp. 267-279. DOI 10.1016/j. cognition.2011.11.011. ISSN 0010-0277.

[46] Saeidi-Mobarakeh, Z., Tavakkoli-Moghaddam, R., Navabakhsh, M. and Amoozad-Khalili, H. (2020) "A bi-level and robust optimisation-based framework for a hazardous waste management problem: A real-world application", Journal of Cleaner Production, Vol. 252. ISSN 0959-6526. DOI 10.1016/j.jclepro.2019.119830.

[47] Shen, W., Qi, R., Zhang, J., Wang, Z., Wang, H., Hu, C., Zhao, Y., Bie, M., Wang, Y., Fu, Y., Chen, M. and Lu, D. (2012) "Chlorogenic acid inhibits LPS-induced microglial activation and improves survival of dopaminergic neurons", Brain Research Bulletin, Vol. 88, pp. 487-494. ISSN 0361-9230. DOI 10.1016/j.brainresbull.2012.04.010.

[48] Shokishalov, Z. and Wang, H. (2019) "Applying Eye Tracking in Information Security", Procedia Computer Science, Vol. 150, pp. 347-351. ISSN 1877-0509. DOI 10.1016/j.procs.2019.02.062.

[49] Schmidt, K., Gamer, M., Forkmann, K. and Bingel, U. (2017) "Pain Affects Visual Orientation: An Eye-Tracking Study", Journal of Pain. ISSN 1526-5900. DOI 10.1016/j.jpain.2017.09.005.

[50] Schotter, E. R., Lee, M., Reiderman, M. and Rayner, K. (2015) "The effect of contextual constraint on parafoveal processing in reading", Journal of Memory and Language, Vol. 83, pp. 118-139. ISSN 0749-596X. DOI 10.1016/j.jml.2015.04.005.

[51] Sim, G., Cassidy, B. and Read, J. C. (2013) "Understanding the fidelity effect when evaluating games with children", $12^{\text {th }}$ International Conference on Interaction Design and Children, New York, pp. 193-200. DOI 10.1145/2485760.2485769. 
[52] Smith, N. J. and Levy, R. (2013) "The effect of word predictability on reading time is logarithmic", Cognition, Vol. 128, No. 3, pp. 302-319. ISSN 0010-0277. DOI 10.1016/j.cognition.2013.02.013.

[53] Stein, J. (2001) "The magnocellular theory of developmental dyslexia", Dyslexia, Vol. 7, No. 1, pp. 12-36. ISSN 1099-0909. DOI 10.1002/dys.186.

[54] Wang, Y., Pan, X., Ye, Y., Li, S., Wang, D. and Liu, Y.-Q. (2019) "Process soptimisation of biomass liquefaction in isopropanol/water with Raney nickel and sodium hydroxide as combined catalysts", Biomass Bioenergy, Vol. 122, pp. 305-312. ISSN 0961-9534. DOI 10.1016/j.biombioe.2019.01.020.

[55] Wang, Y., Wu, K. and Sun, Y. (2018) "Effects of raw material particle size on the briquetting process of rice straw", Journal of the Energy Institute, Vol. 91, No. 1, pp. 153-162. ISSN 1743-9671. DOI 10.1016/j.joei.2016.09.002.

[56] Wigfield, A., Mason-Singh, A., Ho, A. N. and Guthrie, J. (2014) "Intervening to Improve Children's Reading Motivation and Comprehension: Concept-Oriented Reading Instruction", Motivational Interventions (Advances in Motivation and Achievement, Vol. 18, pp. 37-70. ISSN 0749-7423), Emerald Group Publishing Limited, Bingley, pp. 37-70. ISBN 978-1-78350-555-5. DOI 10.1108/S0749-742320140000018001.

[57] Yue, Z. B., Ma, D., Peng, S. C., Zhao, X., Chen, T. H. and Wang, J. (2016) "Integrated sutilisation of algal biomass and corn stover for biofuel production", Fuel, Vol. 168, pp. 1-6. ISSN 0016-2361. DOI 10.1016/j.fuel.2015.11.079. 